\title{
Association between red cell distribution width and the risk of heart events in patients with coronary artery disease
}

\author{
WEIMIN LI $^{1 *}$, XIAOTING LI $^{2 *}$, MAOFENG WANG ${ }^{3 *}$, XUAN GE$^{1}$, FEIXIANG LI ${ }^{1}$, BIAN HUANG $^{1}$, \\ JIREN PENG ${ }^{1}$, GUOHONG LI ${ }^{1}$, LIANG LU ${ }^{1}$, ZHUOYUAN YU ${ }^{1}$, JIAOJIAO MA ${ }^{1}$, \\ LIAOHANG XU ${ }^{1}$, MEIJUAN JIN ${ }^{1}$, HONGPING SI $^{1}$ and RUGEN WAN ${ }^{3}$ \\ ${ }^{1}$ Department of Cardiology, Affiliated Dongyang Hospital of Wenzhou Medical University, Dongyang, Zhejiang 322100; \\ ${ }^{2}$ Department of Cardiology, Sir Run Run Shaw Hospital, School of Medicine, Zhejiang University, Hangzhou, \\ Zhejiang 310000; ${ }^{3}$ Department of Clinical Laboratory Medicine, Affiliated Dongyang Hospital of \\ Wenzhou Medical University, Dongyang, Zhejiang 322100, P.R. China
}

Received May 14, 2014; Accepted January 13, 2015

DOI: $10.3892 / \mathrm{etm} .2015 .2244$

\begin{abstract}
Red cell distribution width (RDW) has been found to be a novel prognostic biomarker in patients with coronary artery disease (CAD); however, the association between RDW and the risk of heart events in patients with CAD is yet to be fully elucidated. Thus, the aim of the present study was to determine whether an elevated RDW was associated with the Framingham risk score (FRS) in patients with CAD. Data were retrospectively collected from Affiliated Dongyang Hospital of Wenzhou Medical University (Dongyang, China). The patients had undergone a coronary angiography and their clinical data were integrated. The patients (male, 260; female, 132) were divided into two groups based on the results of the coronary angiography, namely the CAD $(n=283)$ and control groups $(n=109)$. The FRS was calculated for all the subjects, and complete blood count testing with biochemical measurements was performed. The mean RDW level was $13.7 \pm 1.8 \%$ in the CAD group and $13.1 \pm 1.0 \%$ in the control group, while the mean FRS was $9.0 \pm 4.9$ in the CAD group and 6.4 \pm 3.9 in the control group. The RDW and FRS were significantly higher in the CAD group compared with the control group $(\mathrm{P}<0.001)$. No statistically significant differences were observed between the groups with regard to the hematocrit, mean corpuscular volume, platelets, glucose, urea, albumin, aspartate aminotransferase, total cholesterol, triglycerides (TG), high-density lipoprotein cholesterol, low-density lipoprotein cholesterol and $\mathrm{N}$-terminal pro-brain natriuretic peptide $(\mathrm{P}>0.05)$. The RDW
\end{abstract}

Correspondence to: $\mathrm{Mr}$ Weimin Li, Department of Cardiology, Affiliated Dongyang Hospital of Wenzhou Medical University, 60 Wuning West Road, Dongyang, Zhejiang 322100, P.R. China

E-mail: dyliwm@126.com

*Contributed equally

Key words: red cell distribution width, coronary artery disease, Framingham risk score, heart events was shown to significantly correlate with the red blood cell (RBC) count ( $r=-0.133, \mathrm{P}=0.029)$, hemoglobin level $(r=-0.207$, $\mathrm{P}=0.001)$ and TG level $(r=0.226, \mathrm{P}<0.001)$ within the laboratory parameters, as well as the FRS $(r=0.206, \mathrm{P}<0.001)$. In the stepwise multivariate linear regression, which included the RBC count, hemoglobin level, TG level and RDW, the FRS was predicted by hemoglobin $\left(r^{2}=0.034, \mathrm{P}=0.001\right), \mathrm{TG}$ $\left(r^{2}=0.059, \mathrm{P}<0.001\right)$ and $\mathrm{RDW}\left(r^{2}=0.030, \mathrm{P}=0.003\right)$ parameters. Therefore, a novel association was revealed between higher levels of RDW and an elevated FRS in patients with CAD, which raises the possibility that a simple marker, RDW, may be associated with an increased risk of heart events in CAD patients.

\section{Introduction}

In current clinical practice, one of the most frequently ordered laboratory tests is the complete blood count (CBC). The standard CBC test comprises white blood cell (WBC), red blood cell (RBC) and platelet counts, and their morphological indices. Numerous studies have investigated the efficacy of these hematological CBC parameters in the prediction of disease severity (1) and mortality risk (2). For example, the red cell distribution width (RDW) to platelet ratio has been proposed as a biomarker for liver fibrosis and cirrhosis (3). Furthermore, an increase in RDW has been shown to be associated with mortality and other severe adverse outcomes in cardiac (4-8), renal (9) and infectious diseases (10-12), as well as for individuals in the general population $(13,14)$. Coronary artery disease (CAD) is one of the leading causes of mortality and morbidity $(15,16)$. The gold standard for the diagnosis and selection of therapeutic methods for CAD is an invasive conventional coronary angiography, which outlines the severity and complexity of the CAD $(17,18)$. RDW is a newly identified novel risk marker that has been reported to be a predictor for morbidity and mortality in a variety of cardiovascular conditions $(19,20)$. Previous studies have reported that an elevated RDW is significantly associated with a poor prognosis in patients with heart failure (21) and stable CAD (15). Despite these correlations, a limited number of studies have evaluated 
the association between RDW and the risk of heart events in patients with CAD. Since measuring these indices and evaluating the associations with disease progression and prognosis is relatively simple and cost-effective, the present study aimed to determine whether an elevated RDW was associated with the Framingham risk score (FRS) in patients with CAD. FRS is a well-established risk assessment tool, with a high degree of concordance between expected and actual event frequencies (22)

\section{Subjects and methods}

Ethical approval. The study was approved by the Human Investigation Ethics Committee of the Affiliated Dongyang Hospital of Wenzhou Medical University (Dongyang, China). All the patients provided oral informed consent prior to enrolment in the study.

Subjects and sample collection. Data were retrospectively collected between January 2012 and September 2013 from Affiliated Dongyang Hospital of Wenzhou Medical University. All the patients had undergone a coronary angiography and their clinical data were integrated. The patients (male, 260; female, 132) were divided into two groups based on the results of coronary angiography, namely the CAD $(n=283)$ and control groups $(n=109)$. CAD was defined as stenosis of $\geq 50 \%$ in the left main coronary artery, the left anterior descending artery, the left circumflex coronary artery, the right coronary artery or the main branch of the coronary artery.

All the individuals enrolled in the study, regardless of a CAD diagnosis, exhibited normal hepatic and renal function. Individuals were excluded from the study if they presented with evidence of myocardial infarction, valvular heart disease, left ventricular dysfunction, congestive heart failure, had a history of dysphagia, swallowing and intestinal motility disorders, had untreated thyroid disease, sinus node dysfunction or conduction disturbance, were undergoing estrogen replacement therapy, had an autoimmune disease or had suffered from a recent infection (within the previous three months). Subjects who had a previous history of anemia, were receiving treatment for anemia, including supplementary iron, folate or an erythropoiesis-stimulating agent, or had received a RBC transfusion were also excluded from the study. Furthermore, patients with a known hematological disease, including hemolytic anemia and neoplastic metastases to the bone marrow, or those on iron replacement therapy that may have increased the plasma RDW, were not included in the study.

Baseline clinical and demographic characteristics were obtained from all the patients. A detailed physical examination was performed, which included past medical history, and hematological and clinical data were obtained from the patients. The FRS was calculated by assigning gender-specific points, as recommended by the National Cholesterol Education Program Expert Panel on the Detection, Evaluation, and Treatment of High Blood Cholesterol in Adults (Adult Treatment Panel III) guidelines (23). Hypertension was identified based on previous prescriptions for antihypertensive drugs or when the blood pressure exceeded $140 / 90 \mathrm{mmHg}$ in at least three measurements. Diabetics were defined as having received a prior prescription of antidiabetic medications or having fasting glucose levels of $>7 \mathrm{mmol} / \mathrm{l}$. Current smokers and drinkers were defined as subjects with a positive history of cigarette smoking and alcohol drinking, respectively.

Laboratory analysis. CBC testing was performed using an automated hematology analyzer XE-2100 (Sysmex Corporation, Kobe, Japan) for clinical purposes during the baseline hospitalization. CBC metrics included the hematocrit, hemoglobin levels, RDW, mean corpuscular volume (MCV), and RBC, platelet (PLT) and total WBC counts. The other biochemical measurements were performed using a Hitachi 7600-120 chemical analyzer (Hitachi, Ltd., Tokyo, Japan). N-terminal pro-brain natriuretic peptide (NT-proBNP) analysis was performed with an automated electrochemiluminescence analyzer (Modular Analytics Cobas e601; Roche Diagnostics GmbH, Mannheim, Germany).

Statistical analysis. Data are expressed as the mean \pm standard deviation or the median with the interquartile range, depending on the distribution. Univariate comparisons of continuous variables were performed using a two-sample independent t-test for normally distributed data or non-parametric Mann-Whitney U-test for non-normally distributed variables. For multiple comparisons of several groups, analysis of variance or a Kruskall-Wallis test was performed. The $\chi^{2}$ test was performed for categorical data comparisons. Associations between continuous variables were determined using Pearson's correlation analysis. Since the levels of aspartate aminotransferase (AST), creatine kinase (CK), creatine kinase-MB (CK-MB), lactate dehydrogenase (LDH), C-reactive protein (CRP) and NT-proBNP were not normally distributed, a logarithmic transformation was used. To determine the variables independently associated with the FRS, a stepwise multivariate linear regression was performed, which included the variables that correlated significantly with the FRS. $\mathrm{P}=0.05$ was set as the threshold for inclusion, while $\mathrm{P}=0.10$ was set as the threshold for exclusion of variables. A two-sided P-value of $<0.05$ was considered to indicate a statistically significant difference. Statistical analysis was performed using SPSS software 13.0 (SPSS, Inc., Chicago, IL, USA) for Windows.

\section{Results}

Baseline characteristics. Baseline characteristics of the patients with CAD and the control subjects are shown in Table I. In total, 283 patients were included in the CAD group and 109 individuals were included in the control group, comprising a total of 392 subjects. The mean age was $67 \pm 10$ years in the CAD group and $62 \pm 10$ years in the control group; thus, the age was significantly higher in the CAD group $(\mathrm{P}<0.001)$. In the CAD group, $20.1 \%(57 / 283)$ of patients were diabetic and $68.9 \%(195 / 283)$ were hypertensive. By contrast, in the control group, $11.0 \%(12 / 109)$ of the patients were diabetic and $39.4 \%$ (43/109) were hypertensive. The diabetic and hypertensive rates in the CAD group were significantly higher compared with those in the control group $(\mathrm{P}<0.05)$. No statistically significant differences were observed between the CAD and control groups with regard to gender, body mass index (BMI), smoking and drinking $(\mathrm{P}>0.05)$. 
Table I. Baseline characteristics of the patients and control subjects.

\begin{tabular}{lccr}
\hline Parameters & CAD patients (n=283) & Control subjects (n=109) & P-value \\
\hline Gender, male/female (n) & $194 / 89$ & $66 / 43$ & 0.133 \\
Age (years) & $67 \pm 10$ & $62 \pm 10$ & $<0.001$ \\
BMI (kg/cm²) & $25.2 \pm 4.1$ & $23.9 \pm 3.9$ & 0.420 \\
Current drinking, yes/no (n) & $113 / 170$ & $45 / 64$ & 0.770 \\
Current smoking, yes/no (n) & $138 / 145$ & $46 / 63$ & 0.257 \\
Hypertension, yes/no (n) & $195 / 88$ & $43 / 66$ & $<0.001$ \\
Diabetes, yes/no (n) & $57 / 226$ & $12 / 97$ & 0.038 \\
\hline
\end{tabular}

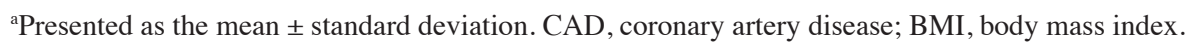

Table II. Hematological and clinical data of the CAD patients and control subjects.

\begin{tabular}{|c|c|c|c|}
\hline Parameters & CAD group $(n=283)$ & Control group $(n=109)$ & P-value \\
\hline $\operatorname{WBC}\left(10^{3} / \mu 1\right)^{\mathrm{a}}$ & $6.60 \pm 2.57$ & $5.79 \pm 1.56$ & 0.002 \\
\hline Neutrophils $(\%)^{\mathrm{a}}$ & $63 \pm 11$ & $59 \pm 9$ & $<0.001$ \\
\hline Lymphocytes $(\%)^{\mathrm{a}}$ & $25 \pm 9$ & $30 \pm 9$ & $<0.001$ \\
\hline $\operatorname{RBC}\left(10^{6} / \mu 1\right)^{\mathrm{a}}$ & $4.22 \pm 0.62$ & $4.37 \pm 0.54$ & 0.030 \\
\hline Hemoglobin $(g / l)^{\mathrm{a}}$ & $128 \pm 18$ & $135 \pm 31$ & 0.012 \\
\hline Hematocrit $(\%)^{\mathrm{a}}$ & $0.49 \pm 0.04$ & $0.40 \pm 0.04$ & 0.609 \\
\hline $\operatorname{MCV}(\mathrm{fl} / \text { cell })^{\mathrm{a}}$ & $91 \pm 5$ & $92 \pm 5$ & 0.303 \\
\hline $\operatorname{RDW}(\%)^{\mathrm{a}}$ & $13.7 \pm 1.8$ & $13.1 \pm 1.0$ & 0.001 \\
\hline $\operatorname{PLT}\left(10^{3} / \mu 1\right)^{\mathrm{a}}$ & $182 \pm 95$ & $178 \pm 56$ & 0.678 \\
\hline Glucose $(\mathrm{mmol} / \mathrm{l})^{\mathrm{a}}$ & $5.5 \pm 1.4$ & $5.3 \pm 1.3$ & 0.186 \\
\hline Urea $(\mathrm{mmol} / \mathrm{l})^{\mathrm{a}}$ & $5.8 \pm 2.2$ & $5.5 \pm 1.9$ & 0.210 \\
\hline Creatinine $(\mu \mathrm{mol} / 1)^{\mathrm{a}}$ & $83 \pm 27$ & $75 \pm 27$ & 0.009 \\
\hline $\operatorname{Albumin}(\mathrm{g} / \mathrm{l})^{\mathrm{a}}$ & $38 \pm 7.8$ & $39 \pm 7$ & 0.094 \\
\hline $\operatorname{AST}(\mathrm{U} / 1)^{\mathrm{b}}$ & $21(17-32)$ & $21(16-25)$ & 0.176 \\
\hline $\mathrm{CK}(\mathrm{U} / 1)^{\mathrm{b}}$ & $79(55-158)$ & $73(54-98)$ & 0.019 \\
\hline CK-MB (U/1) ${ }^{\mathrm{b}}$ & $12(9-18)$ & $11(9-14)$ & 0.011 \\
\hline $\mathrm{LDH}(\mathrm{U} / \mathrm{l})^{\mathrm{b}}$ & $167(140-215)$ & $157(131-181)$ & 0.007 \\
\hline $\mathrm{TC}(\mathrm{mmol} / \mathrm{l})^{\mathrm{a}}$ & $4.23 \pm 1.09$ & $4.05 \pm 0.88$ & 0.813 \\
\hline $\mathrm{TG}(\mathrm{mmol} / \mathrm{l})^{\mathrm{a}}$ & $1.45 \pm 0.86$ & $1.39 \pm 0.78$ & 0.894 \\
\hline $\mathrm{HDL}-\mathrm{C}(\mathrm{mmol} / \mathrm{l})^{\mathrm{a}}$ & $1.00 \pm 0.31$ & $1.02 \pm 0.22$ & 0.943 \\
\hline LDL-C (mmol/l $)^{\mathrm{a}}$ & $2.45 \pm 0.91$ & $2.41 \pm 0.82$ & 0.682 \\
\hline $\mathrm{CRP}(\mathrm{mg} / \mathrm{l})^{\mathrm{b}}$ & $1.60(0.40-7.35)$ & $0.64(0.30-1.60)$ & $<0.001$ \\
\hline NT-proBNP $(\mathrm{pg} / \mathrm{ml})^{\mathrm{b}}$ & $613(149.8-2295)$ & $416(95.6-1320)$ & 0.079 \\
\hline FRS $^{\mathrm{a}}$ & $9.0 \pm 4.9$ & $6.4 \pm 3.9$ & $<0.001$ \\
\hline
\end{tabular}

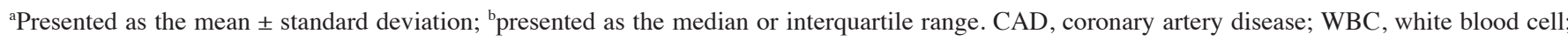
RBC, red blood cell; MCV, mean corpuscular volume; RDW, red cell distribution width; PLT, platelet; AST, aspartate aminotransferase; CK, creatine kinase; CK-MB, creatine kinase-MB; LDH, lactate dehydrogenase; TC, total cholesterol; TG, triglycerides; HDL-C, high-density lipoprotein cholesterol; LDL-C, low-density lipoprotein cholesterol; CRP, C-reactive protein; NT-proBNP, N-terminal pro-brain natriuretic peptide; FRS, Framingham risk score.

Laboratory observations. No statistically significant differences were observed between the groups with regard to the hematocrit, MCV, PLT count, and levels of glucose, urea, albumin, AST, total cholesterol (TC), triglyceride (TG), high-density lipoprotein cholesterol (HDL-C), low-density lipoprotein cholesterol (LDL-C) and NT-proBNP. The mean RDW was $13.7 \pm 1.8 \%$ in the CAD group and $13.1 \pm 1.0 \%$ in the control group; thus, the RDW was significantly higher in the CAD group when compared with the control group $(\mathrm{P}<0.001)$.
The mean FRS was $9.0 \pm 4.9$ in the CAD group and $6.4 \pm 3.9$ in the control group; the FRS was significantly higher in the CAD group compared with the control group $(\mathrm{P}<0.001)$. Furthermore, patients in the CAD group had significantly higher levels of WBCs, neutrophils, creatinine, CK, CK-MB, LDH and CRP, and lower levels of lymphocytes, RBC and hemoglobin when compared with the levels in the control group. Table II shows the hematological and clinical data of the patients with CAD and the control subjects. 
Table III. Hematological and clinical data of all the subjects differentiated by diabetic and hypertensive conditions.

\begin{tabular}{|c|c|c|c|c|}
\hline Parameters & Diabetic and hypertensive & Diabetic or hypertensive & Not diabetic or hypertensive & P-value \\
\hline $\operatorname{WBC}\left(10^{3} / \mu 1\right)$ & $6.30 \pm 2.37$ & $6.51 \pm 2.25$ & $6.40 \pm 2.41$ & 0.821 \\
\hline Neutrophils (\%) & $62 \pm 10$ & $63 \pm 11$ & $63 \pm 11$ & 0.918 \\
\hline Lymphocytes (\%) & $27 \pm 9$ & $26 \pm 10$ & $27 \pm 10$ & 0.474 \\
\hline $\operatorname{RBC}\left(10^{6} / \mu 1\right)$ & $4.35 \pm 0.63$ & $4.29 \pm 0.64$ & $4.18 \pm 0.55$ & 0.060 \\
\hline Hemoglobin (g/l) & $135 \pm 32$ & $129 \pm 20$ & $131 \pm 25$ & 0.609 \\
\hline RDW $(\%)$ & $13.4 \pm 1.0$ & $13.5 \pm 0.9$ & $13.6 \pm 1.2$ & 0.763 \\
\hline Creatinine $(\mu \mathrm{mol} / \mathrm{l})$ & $83.8 \pm 26.3$ & $83.4 \pm 31.3$ & $78.1 \pm 26.2$ & 0.245 \\
\hline $\mathrm{CK}(\mathrm{U} / \mathrm{l})$ & $79(51-137)$ & $77(54-126)$ & $81(52-132)$ & 0.090 \\
\hline LDH (U/l) & $165(135-208)$ & $158(131-202)$ & $164(137-191)$ & 0.125 \\
\hline $\mathrm{CRP}(\mathrm{mg} / \mathrm{l})$ & $1.32(0.44-5.10)$ & $1.20(0.37-4.40)$ & $1.26(0.46-4.80)$ & 0.962 \\
\hline FRS & $8.9 \pm 4.2$ & $8.2 \pm 4.1$ & $7.9 \pm 3.1$ & 0.001 \\
\hline
\end{tabular}

WBC, white blood cell; RBC, red blood cell; RDW, red cell distribution width; CK, creatine kinase; LDH, lactate dehydrogenase; CRP, C-reactive protein; FRS, Framingham risk score.

Table IV. Correlation coefficients of hematological and clinical variables with RDW in patients with CAD.

\begin{tabular}{|c|c|c|}
\hline \multirow[b]{2}{*}{ Variables } & \multicolumn{2}{|c|}{ RDW } \\
\hline & $r$ & P-value \\
\hline Age & 0.076 & 0.212 \\
\hline BMI & 0.132 & 0.355 \\
\hline WBC & -0.072 & 0.236 \\
\hline Neutrophils & -0.051 & 0.406 \\
\hline Lymphocytes & 0.059 & 0.329 \\
\hline $\mathrm{RBC}$ & -0.133 & 0.029 \\
\hline Hemoglobin & -0.207 & 0.001 \\
\hline Hemotocrit & -0.023 & 0.705 \\
\hline $\mathrm{MCV}$ & -0.118 & 0.052 \\
\hline PLT & 0.055 & 0.370 \\
\hline Glucose & 0.040 & 0.509 \\
\hline Urea & 0.062 & 0.311 \\
\hline Creatinine & 0.023 & 0.703 \\
\hline Albumin & -0.010 & 0.873 \\
\hline AST & -0.019 & 0.757 \\
\hline CK & -0.026 & 0.665 \\
\hline CKMB & -0.005 & 0.934 \\
\hline LDH & 0.001 & 0.991 \\
\hline $\mathrm{TC}$ & 0.017 & 0.775 \\
\hline TG & 0.226 & $<0.001$ \\
\hline HDL-C & -0.031 & 0.608 \\
\hline LDL-C & -0.065 & 0.290 \\
\hline CRP & -0.017 & 0.814 \\
\hline NT-proBNP & 0.019 & 0.817 \\
\hline FRS & 0.206 & $<0.001$ \\
\hline
\end{tabular}

$\mathrm{CAD}$, coronary artery disease; $\mathrm{BMI}$, body mass index; $\mathrm{WBC}$, white blood cell; RBC, red blood cell; MCV, mean corpuscular volume; RDW, red cell distribution width; PLT, platelet; AST, aspartate aminotransferase; $\mathrm{CK}$, creatine kinase; $\mathrm{CK}-\mathrm{MB}$, creatine kinase-MB; LDH, lactate dehydrogenase; TC, total cholesterol; TG, triglycerides; HDL-C, high-density lipoprotein cholesterol; LDL-C, low-density lipoprotein cholesterol; CRP, C-reactive protein; NT-proBNP, N-terminal pro-brain natriuretic peptide; FRS, Framingham risk score.
Hematological and clinical data of the diabetic and hypertensive patients. No statistically significant differences were observed between the two groups with regard to the levels of WBCs, neutrophils, lymphocytes, RBCs, hemoglobin, RDW,

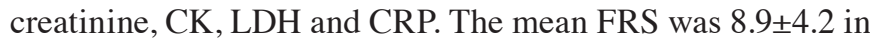
the diabetic and hypertensive group, $8.2 \pm 4.1$ in the diabetic or hypertensive group and $7.9 \pm 3.1$ in the group with no subjects with diabetes or hypertension. The FRS was significantly different among the three groups $(\mathrm{P}=0.001)$. Table III shows the hematological and clinical data for all the subjects, differentiated by diabetic and hypertensive conditions.

Associations between the RDW and laboratory parameters. Correlations between the RDW and laboratory parameters or the FRS were investigated (Table IV and Fig. 1). The RDW was shown to significantly correlate with the RBC count $(r=-0.133, \mathrm{P}=0.029)$, hemoglobin level $(r=-0.207, \mathrm{P}=0.001)$ and TG level $(r=0.226, \mathrm{P}<0.001)$ within the laboratory parameters, as well as the FRS ( $r=0.206, \mathrm{P}<0.001)$. However, other parameters, including age, BMI, WBC, MCV, PLT, creatinine, TC, HDL-C, LDL-C, CRP and NT-proBNP did not exhibit a statistically significant correlation with the RDW. In the stepwise multivariate linear regression, which included the RBC count, hemoglobin level, TG level and RDW, the FRS was predicted by hemoglobin $\left(r^{2}=0.034, \mathrm{P}=0.001\right)$, TG $\left(r^{2}=0.059, \mathrm{P}<0.001\right)$ and RDW $\left(r^{2}=0.030, \mathrm{P}=0.003\right)$. Table $\mathrm{V}$ shows the results from the stepwise multivariate linear regression for FRS in patients with CAD.

\section{Discussion}

In the present study, the RDW and FRS were demonstrated to be significantly higher in the CAD group when compared with the control group. In addition, the RDW was shown to significantly correlate with the RBC count, hemoglobin level and TG level within the laboratory parameters, and significantly correlate with the FRS. Furthermore, the FRS was predicted by hemoglobin levels, TG and RDW in patients with CAD, and the RDW, TG and hemoglobin levels were found to 
Table V. Stepwise multivariate linear regression for FRS in patients with CAD.

\begin{tabular}{|c|c|c|c|c|}
\hline Variables & $\beta$ coefficient & Standard error & Partial $r^{2}$ & P-value \\
\hline RDW & 0.076 & 0.025 & 0.030 & 0.003 \\
\hline $\mathrm{TG}$ & 0.473 & 0.111 & 0.059 & $<0.001$ \\
\hline Hemoglobin & -0.019 & 0.006 & 0.034 & 0.001 \\
\hline
\end{tabular}

RDW, red cell distribution width; TG, triglyceride; FRS, Framingham risk score; CAD, coronary artery disease.
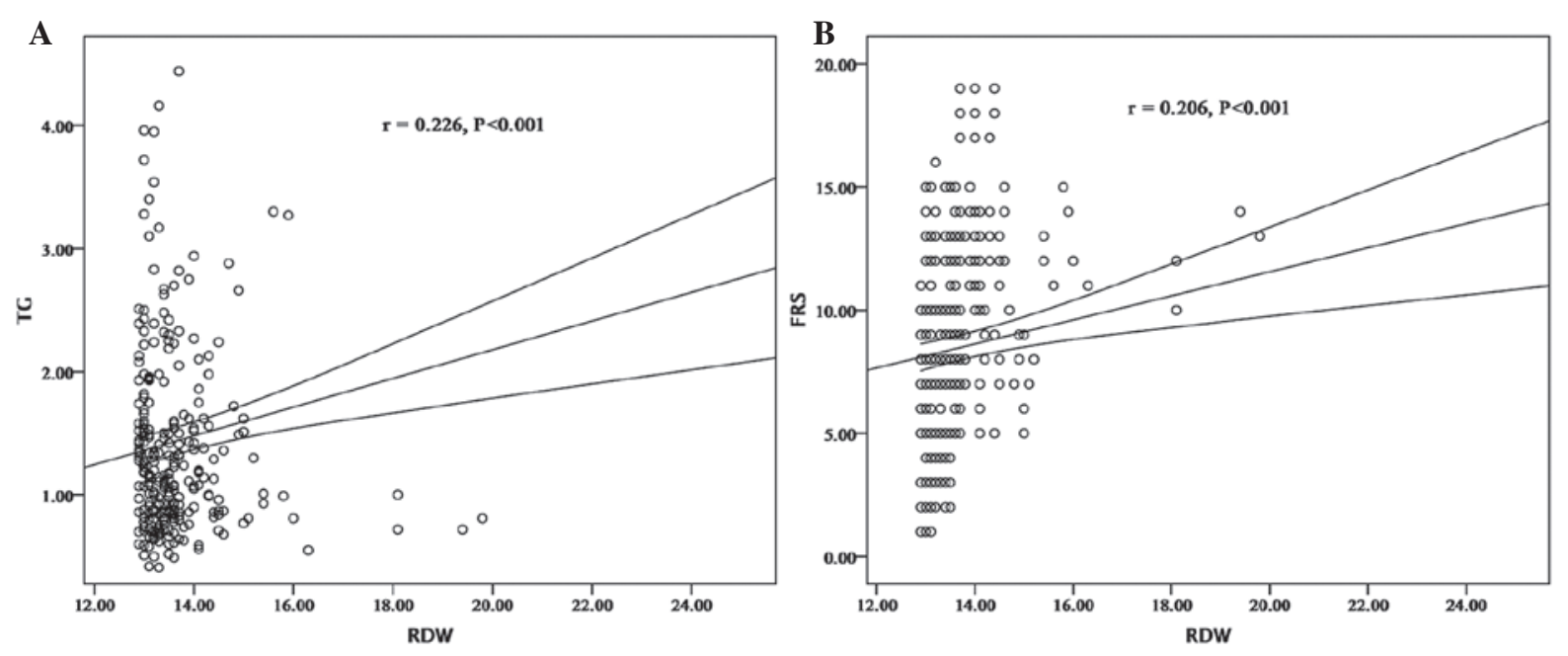

Figure 1. Correlation between RDW and (A) TG and (B) FRS. RDW, red cell distribution width; TG, triglycerides, FRS, Framingham risk score.

be potentially useful predictors of future cardiovascular risk events in patients with CAD.

The RDW, as measured by a hematology analyzer, is an index of the variation in RBC size. An elevated RDW indicates immature RBC production in the bone marrow (24); thus, an increased RDW is often observed in patients with hematological diseases, including vitamin B12 or folate deficiency or hemolysis. Therefore, subjects were excluded from the current study if they had a history of anemia, had received a previous $\mathrm{RBC}$ transfusion or were receiving treatment for anemia, including supplementary iron, folate or an erythropoiesis-stimulating agent. Although diabetes and hypertension are known factors that influence the RDW (25), in the present study, no statistically significant differences were observed among the diabetic and hypertensive patients with regard to the RDW compared with the non-hypertensive and non-diabetic subjects. The elevated RDW observed in the study group was not considered to result from diabetic or hypertensive conditions.

Several possible mechanisms exist for an elevated RDW in patients with acute pancreatitis. For example, an increased RDW in patients with CAD may be associated with inflammation (26). Persistent inflammation is known to be a principal pathophysiological observation and a poor prognostic factor for patients with CAD (27). A possible correlation between the RDW and the severity and characteristics of inflammation may exist; therefore, a theoretical explanation for the elevated RDW observed in the study group may be an aggravated inflammatory status. A statistically significant difference in CRP levels was observed between the patients with CAD and the control subjects, although the CRP level did not exhibit a significant correlation with the RDW. Chronic subclinical inflammation is a well-established entity that precedes de novo cardiovascular events (28-30). The condition may adversely affect erythropoiesis via a number of mechanisms, such as the direct myelosuppression of erythroid precursors, reducing renal erythropoietin production and the bioavailability of iron, increasing erythropoietin resistance in erythroid precursor cell lines, and also through the promotion of cell apoptosis (27). Therefore, anisocytosis may result from inflammation via the release of immature RBCs into the peripheral circulation. Increased RDW values have been found to be independently associated with higher levels of CRP, a known surrogate marker of inflammation, as well as a number of additional inflammatory markers, including interleukin-6 and soluble tumor necrosis factor receptors 1 and $2(31,32)$. The current findings, however, conflicted with the observations of Zalawadiya et al (33), who found that CRP levels increased linearly with increased RDW quartiles. The precise causes responsible for the difference in the reported association are yet to be elucidated; however, ethnic differences in CAD risk prediction and differences in population characteristics or sample size are hypothesized to play a role.

Mechanisms underlying the association between the RDW and the increase in CAD cardiovascular events remain speculative. However, elevated RDWs have been demonstrated to be associated with increased hemodynamic and oxidative stress, which is characteristic of CAD exacerbation (34). Previously, 
the concept of RDW as a prognostic marker for patients with $\mathrm{CAD}$, and as a predictor for the development of CAD in patients with cardiovascular disease, has been proposed by a number of studies $(15,16)$. However, the mechanisms underlying these novel observations have not been fully elucidated; thus, further study is required. In line with this perspective, the present study hypothesized that higher levels of RDW were associated with the FRS in patients with CAD.

An increased FRS represents the aggravation of risk in patients with CAD (33). The estimation of heart events is important for the management of patients with CAD in clinical practice. Although the present study had a number of limitations, including the unavailability of data regarding actual cardiovascular events during a set follow-up period, the FRS is a well-established risk assessment tool that has a high degree of concordance between the expected and actual event frequencies, which supports the validity of the study observations. Furthermore, the RDW was shown to significantly correlate with the FRS, which is known to correlate strongly with TG levels, TC and smoking. Therefore, the observations of the present study indicate that this simple measurement of RDW may be useful for estimating an elevated FRS in patients with CAD. Future study should focus on specifically investigating the use of RDW to reclassify patients in the intermediate FRS category.

In conclusion, a potential association was identified between the RDW and an increased FRS, which was suggestive of elevated cardiovascular events in patients with CAD. Furthermore, the present study demonstrated that RDW, a simple and inexpensive test, in collaboration with additional biomarkers, may be a useful method for the assessment of cardiovascular event risk changes in patients with CAD.

\section{Acknowledgements}

This study was supported by grants from the Jinhua Municipal Science and Technology Bureau, Zhejiang, China (no. 2012-3-087) and the Health Bureau of Zhejiang Province, China (no. 2014KYA221). The authors thank the nurses, residents and consultants from the Department of Cardiology (Affiliated Dongyang Hospital of Wenzhou Medical University) who were involved in the management of patients, and all the patients who participated in the study.

\section{References}

1. Rhodes CJ, Wharton J, Howard LS, Gibbs JS and Wilkins MR: Red cell distribution width outperforms other potential circulating biomarkers in predicting survival in idiopathic pulmonary arterial hypertension. Heart 97: 1054-1060, 2011.

2. Sičaja M, Pehar M, Đerek L, et al: Red blood cell distribution width as a prognostic marker of mortality in patients on chronic dialysis: a single center, prospective longitudinal study. Croat Med J 54: 25-32, 2013.

3. Chen B, Ye B, Zhang J, Ying L and Chen Y: RDW to platelet ratio: a novel noninvasive index for predicting hepatic fibrosis and cirrhosis in chronic hepatitis B. PLoS One 8: e68780, 2013.

4. Oh J, Kang SM, Hong N, et al: Relation between red cell distribution width with echocardiographic parameters in patients with acute heart failure. J Card Fail 15: 517-522, 2009.

5. Adams KF Jr, Mehra MR, Oren RM, et al: Prospective evaluation of the association between cardiac troponin $\mathrm{T}$ and markers of disturbed erythropoiesis in patients with heart failure. Am Heart J 160: 1142-1148, 2010.
6. Isik T, Kurt M, Ayhan E, et al: Relation of red cell distribution width with presence and severity of coronary artery ectasia. Clin Appl Thromb Hemost 18: 441-447, 2012.

7. Warwick R, Mediratta N, Shaw M, et al: Red cell distribution width and coronary artery bypass surgery. Eur J Cardiothorac Surg 43: 1165-1169, 2013.

8. Uyarel H, Ergelen M, Cicek G, et al: Red cell distribution width as a novel prognostic marker in patients undergoing primary angioplasty for acute myocardial infarction. Coron Artery Dis 22: 138-144, 2011.

9. Ujszaszi A, Molnar MZ, Czira ME, Novak M and Mucsi I: Renal function is independently associated with red cell distribution width in kidney transplant recipients: a potential new auxiliary parameter for the clinical evaluation of patients with chronic kidney disease. Br J Haematol 161: 715-725, 2013.

10. Sanz-Peláez O, Angel-Moreno A, Tapia-Martin M, et al: Reference values in the usual laboratory data for sub-Saharan immigrants. Importance in the management of infectious diseases. Rev Clin Esp 208: 386-392, 2008 (In Spanish).

11. Karagöz E and Tanoglu A: Red blood cell distribution width: an emerging diagnostic factor of acute appendicitis? World J Emerg Surg 8: 54, 2013.

12. Lee JH, Chung HJ, Kim K, et al: Red cell distribution width as a prognostic marker in patients with community-acquired pneumonia. Am J Emerg Med 31: 72-79, 2013.

13. Braun E, Domany E, Kenig Y, Mazor Y, Makhoul BF and Azzam ZS: Elevated red cell distribution width predicts poor outcome in young patients with community acquired pneumonia. Crit Care 15: R194, 2011.

14. Hong CH, Falvey C, Harris TB, et al: Anemia and risk of dementia in older adults: findings from the Health $\mathrm{ABC}$ study. Neurology 81: 528-533, 2013

15. Osadnik T, Strzelczyk J, Hawranek M, et al: Red cell distribution width is associated with long-term prognosis in patients with stable coronary artery disease. BMC Cardiovasc Disord 13: 113, 2013.

16. Isik T, Uyarel H, Tanboga IH, et al: Relation of red cell distribution width with the presence, severity and complexity of coronary artery disease. Coron Artery Dis 23: 51-56, 2012.

17. Vorre MM and Abdulla J: Diagnostic accuracy and radiation dose of CT coronary angiography in atrial fibrillation: systematic review and meta-analysis. Radiology 267: 376-386, 2013.

18. Schlattmann P, Schuetz GM and Dewey M: Influence of coronary artery disease prevalence on predictive values of coronary CT angiography: a meta-regression analysis. Eur Radiol 21: 1904-1913, 2011.

19. Rickard J, Kumbhani DJ, Gorodeski EZ, et al: Elevated red cell distribution width is associated with impaired reverse ventricular remodeling and increased mortality in patients undergoing cardiac resynchronization therapy. Congest Heart Fail 18: 79-84, 2012.

20. Özcan F, Turak O, Avci S, et al: Heart rate variability and red cell distribution width in patients with systolic left heart failure. Scand Cardiovasc J 47: 225-229, 2013.

21. Olivares Jara M, Santas Olmeda E, Minaña Escrivà G, et al: Red cell distribution width and mortality risk in acute heart failure patients. Med Clin (Barc) 140: 433-438, 2013 (In Spanish).

22. Zalawadiya SK, Veeranna V, Niraj A, et al: Red cell distribution width and risk of coronary heart disease events. Am J Cardiol 106: 988-993, 2010.

23. McKenney JM: Update on the National Cholesterol Education Program Adult Treatment Panel III guidelines: getting to goal. Pharmacotherapy 23: S26-S33, 2003.

24. Shehata HA, Ali MM, Evans-Jones JC, Upton GJ and Manyonda IT: Red cell distribution width (RDW) changes in pregnancy. Int J Gynaecol Obstet 62: 43-46, 1998.

25. Kucukdurmaz Z, Karavelioglu Y, Karapinar H, et al: Red cell distribution width and hypertensive response to exercise in patients with type 2 diabetes mellitus. Clin Exp Hypertens 36: 32-35, 2014

26. Şenol K, Saylam B, Kocaay F and Tez M: Red cell distribution width as a predictor of mortality in acute pancreatitis. Am J Emerg Med 31: 687-689, 2013.

27. McPherson R and Davies RW: Inflammation and coronary artery disease: insights from genetic studies. Can J Cardiol 28: 662-666, 2012.

28. Santos MJ and Fonseca JE: Metabolic syndrome, inflammation and atherosclerosis-the role of adipokines in health and in systemic inflammatory rheumatic diseases. Acta Reumatol Port 34: 590-598, 2009. 
29. Zambon A, Pauletto P and Crepaldi G: Review article: the metabolic syndrome - a chronic cardiovascular inflammatory condition. Aliment Pharmacol Ther 22 (Suppl 2): 20-23, 2005.

30. Tracy RP: Inflammation markers and coronary heart disease. Curr Opin Lipidol 10: 435-441, 1999.

31. Lippi G, Targher G, Montagnana M, Salvagno GL, Zoppini G and Guidi GC: Relation between red blood cell distribution width and inflammatory biomarkers in a large cohort of unselected outpatients. Arch Pathol Lab Med 133: 628-632, 2009.
32. Förhécz Z, Gombos T, Borgulya G, Pozsonyi Z, Prohászka Z and Jánoskuti L: Red cell distribution width in heart failure: prediction of clinical events and relationship with markers of ineffective erythropoiesis, inflammation, renal function and nutritional state. Am Heart J 158: 659-666, 2009.

33. Zalawadiya SK, Veeranna V, Niraj A, Pradhan J and Afonso L: Red cell distribution width and risk of coronary heart disease events. Am J Cardiol 106: 988-993, 2010.

34. Berliner JA, Navab M, Fogelman AM, et al: Atherosclerosis: basic mechanisms. Oxidation, inflammation and genetics. Circulation 91: 2488-2496, 1995. 